\title{
Dendritic cells in atherosclerotic inflammation: the complexity of functions and the peculiarities of pathophysiological effects
}

\section{Dimitry A. Chistiakov' ${ }^{1}$, Igor A. Sobenin ${ }^{2,3,4}$, Alexander N. Orekhov ${ }^{2,3}$ and Yuri V. Bobryshev ${ }^{2,5 *}$}

1 Department of Medical Nanobiotechnology, Pirogov Russian State Medical University, Moscow, Russia

2 Skolkovo Innovative Center, Institute for Atherosclerosis Research, Moscow, Russia

${ }^{3}$ Institute of General Pathology and Pathophysiology, Russian Academy of Sciences, Moscow, Russia

${ }^{4}$ Laboratory of Medical Genetics, Russian Cardiology Research and Production Complex, Moscow, Russia

${ }^{5}$ Faculty of Medicine, School of Medical Sciences, University of New South Wales, Kensington, Sydney, NSW, Australia

\section{Edited by:}

Mariappan Muthuchamy, Texas A\&M Health Science Center, USA

Reviewed by:

Sanjukta Chakraborty, Texas A\&M Health Science Center, USA

Shenyuan Zhang, Texas A\&M

University, Health Science Center, USA

\section{*Correspondence:}

Yuri V. Bobryshev, Faculty of

Medicine, University of New South

Wales, High Street UNSW, Sydney,

NSW 2052, Australia

e-mail:y.bobryshev@unsw.edu.au
Atherosclerosis is considered as a chronic disease of arterial wall, with a strong contribution of inflammation. Dendritic cells (DCs) play a crucial role in the initiation of proatherogenic inflammatory response. Mature DCs present self-antigens thereby supporting differentiation of naïve $T$ cells to effector cells that further propagate atherosclerotic inflammation. Regulatory $T$ cells (Tregs) can suppress proinflammatory function of mature DCs. In contrast, immature DCs are able to induce Tregs and prevent differentiation of naïve $T$ cells to proinflammatory effector $T$ cells by initiating apoptosis and anergy in naïve T cells. Indeed, immature DCs showed tolerogenic and anti-inflammatory properties. Thus, DCs play a double role in atherosclerosis: mature DCs are proatherogenic while immature DCs appear to be anti-atherogenic. Tolerogenic and anti-inflammatory capacity of immature DCs can be therefore utilized for the development of new immunotherapeutic strategies against atherosclerosis.

Keywords: atherosclerosis, atherogenesis, inflammation, immune reactions, dendritic cells, arteries

\section{INTRODUCTION}

Dendritic cells (DCs) were first described by Steinman and Cohn (1973). DCs are a heterogeneous group of professional antigenpresenting cells (APCs). DCs differentiate from precursors circulating in the bloodstream (Sorg et al., 1999). The precursors can be delivered by blood to the target non-lymphoid organ or tissue, in which they become immature DCs. Immature DCs express on their surface integrin alpha $\mathrm{X}$ (CD11c) (Sorg et al., 1999). However, costimulatory molecules CD80/CD86 essential for $\mathrm{T}$ cell activation are not or expressed or produced at very low levels (Cocks et al., 1995) (Figure 1). Indeed, immature DCs can capture antigens but are not able to stimulate naïve $\mathrm{T}$ cells. From the target tissue, immature DCs in turn migrate to lymphoid organs such as spleen and lymph nodes in which they differentiate into mature DCs. The maturation is accompanied by enhanced expression of costimulatory molecules CD80/86 and CD40, antigen-presenting molecules (MHC class I and II), and

\footnotetext{
Abbreviations: APCs, antigen-presenting cells; apo (Apo), apolipoprotein; C. pneumonia, Chlamydia pneumonia; CCL, CC-motif chemokines; CCR, chemokine receptors; CD, cluster of differentiation; cDCs, myeloid DCs; CTLA-4, cytotoxic T-lymphocyte antigen-4; DC, Dendritic cell; DCs, Dendritic cells; DNA, deoxyribonucleic acid; FoxP3, forkhead box P3; IDO, indoleamine 2,3-dioxigenase; IL, interleukin; iTregs, FoxP3+ Tregs; LDL, low density lipoprotein; LDLR, LDL receptor; LFA-1, lymphocyte function-associated antigen 1; M-CSF, macrophagecolony stimulating factor; MDA-LDL, malonaldehyde-modified LDL; MHC, major histocompatibility complex; NKT cells, natural killer T cells; NZW, New Zealand White; oxLDL, oxidized LDL; pDCs, plasmacytoid DCs; PDL-1, programmed death ligand 1; Scid, severe combined immunodeficiency syndrome; TGFßRII, tumor factor growth- $\beta$ receptor II; Th, T helper; $\operatorname{Tr} 1$, type 1 regulatory $\mathrm{T}$ cells; Tregs, regulatory T cells; VSMCs, vascular smooth muscle cells.
}

adhesion molecules (CD11a, CD50, CD54, CD86). Mature DCs can contact and present antigens to naïve $\mathrm{T}$ cells, which in turn differentiate into effector T cells such Thelper 1 (Th1) or 2 (Th2) cells. DCs also secrete interleukin (IL)-12, a proinflammatory cytokine that directs differentiation of naïve $\mathrm{T}$ cells to effector $\mathrm{T}$ cells (Kubin et al., 1994). Some immature DCs exhibit tolerogenic properties through the induction of regulatory $\mathrm{T}$ cells (Tregs) and suppression of naïve $\mathrm{T}$ cell activation (Steinman et al., 2003).

Atherosclerosis is a chronic inflammatory disease, with a pathogenic immune response driven by $\mathrm{T}$ lymphocytes (Hansson and Hermansson, 2011). Due to their critical role in effector $\mathrm{T}$ cell differentiation from naïve $\mathrm{T}$ cells, it is not surprisingly that DCs are found to be the key players in the proinflammatory response at the atherosclerotic plaque. The discovery of the presence of DCs in the intima of normal arteries and atherosclerotic lesions led to a suggestion that DCs might play an important role in the development of atherosclerotic lesions (Bobryshev and Lord, 1995a,b). An entire network of HLA-DRexpressing cells was eventually found to exist in the intimal space of normal human aortas (Bobryshev et al., 2012), suggesting their potential role in the regulation of vascular homeostasis. The architectonics of this network may be different in various aortic segments thereby predicting putative atherosclerosis-prone and atherosclerosis-resistant regions of the visually normal aorta (Bobryshev and Lord, 1995a).

The involvement of DCs in atherogenesis was then proven by experimental findings on two rodent atherosclerosis models such as apolipoprotein (apo) E-null and LDL receptor (LDLR)-null 


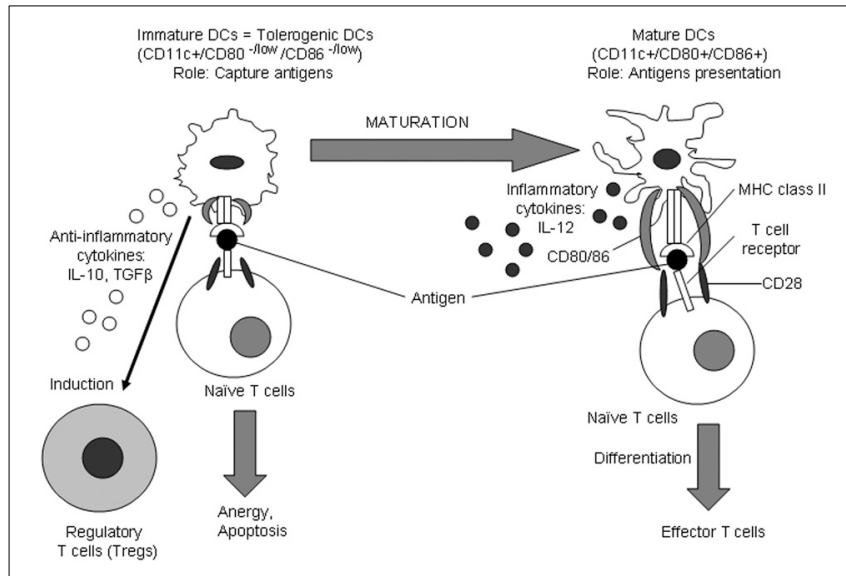

FIGURE 1 | Immature and mature DCs. Immature DCs arise from DC precursors that circulate in the blood. From the blood, DC precursors may reach the target tissue where they transform into immature DCs. The major function of immature DCs is the capture of antigens. Immature DCs capturing antigens may then migrate into lymphoid tissues such as the spleen and lymph nodes where they further differentiate becoming mature DCs. Mature DCs are capable to efficiently present captured antigens to naïve T cells. DC maturation is characterized by the up-regulation of expression of molecules responsible for antigen presentation such as $\mathrm{MHC}$ class II and CD80/CD86. After antigen recognition, naïve T cells differentiate into effector $T$ cells. Differentiation of naïve $T$ cells to effector cells may occur upon cell-cell contacts between a DC and a naïve T cell and via proinflammatory cytokine IL-12 secreted by mature DCs. Immature DCs lacking sufficient expression of antigen-presenting molecules cause anergy and apoptosis of naïve T cells. Immature DCs possess tolerogenic properties by inducing Tregs through cell-to-cell contact with naïve $T$ cells and through secreting anti-inflammatory cytokines such as IL-10 and TGF- $\beta$ Since immature DCs are capable to induce Tregs and inhibit the inflammatory reaction in the atherosclerotic plaque, the development of strategies for the induction of tolerogenic DCs is of great therapeutic promise.

mice (Bobryshev et al., 1999; Paulson et al., 2010). Transfer of oxidized low density lipoprotein (oxLDL)-reactive $\mathrm{T}$ cells to ApoE-null severe combined immunodeficiency syndrome (Scid) mice are more effective in plaque presentation compared to the transport of non-specific $\mathrm{T}$ cells to an antigen derived from a lesion (Zhou et al., 2006), thereby suggesting on the involvement of those cells in presenting antigens in disease progression. DCs were observed in atherosclerotic lesions of apoE- (Bobryshev et al., 1999, 2001) and LDLR-null mice (Paulson et al., 2010), and these cells were not present in the plaques just accidentally but accumulated and contributed to the intraplaque inflammation and progression of the coronary atheroma (Ludewig et al., 2000; Hjerpe et al., 2010).

Since the identification of DCs in the arterial wall (Bobryshev and Lord, 1995a,b), the functional significance of this cell type has been intensely studied and various issues of the involvement of DCs in atherogenesis have been discussed in a number of reviews (Bobryshev, 2000, 2005, 2010; Cybulsky and JongstraBilen, 2010; Niessner and Weyand, 2010; Koltsova and Ley, 2011; Manthey and Zernecke, 2011; Van Vré et al., 2011; Butcher and Galkina, 2012; Feig and Feig, 2012; Takeda et al., 2012; AlbertsGrill et al., 2013; Cartland and Jessup, 2013; Grassia et al., 2013;
Koltsova et al., 2013; Subramanian and Tabas, 2014). It is important to note here that functions of DCs in human arteries are still practically unknown and that the accumulated information about functions of DCs in atherosclerosis is obtained in experimental studies. However, in contrast to the intima of human arteries which contains the nets of DCs (Bobryshev and Lord, 1995a; Bobryshev, 2000), the intima of large arteries in animal models of atherosclerosis consists of the endothelium that is separated from the internal elastic membrane by just a narrow layer of free-of-cell matrix. In humans, the activation of resident vascular DCs occurs in the very earlier stage of atherosclerosis (Bobryshev and Lord, 1995a; Bobryshev, 2000), whereas the accumulation of DCs in the arterial intima in animal models of atherosclerosis occurs as a result of the penetration of DCs or DC precursors from the blood stream, parallel with the development of atherosclerotic lesions (Bobryshev et al., 1999, 2001). Likewise, little is known about the peculiarities of functions of immature DCs $v s$ mature DCs in human atherosclerosis (Bobryshev, 2010).

Accumulated evidence obtained in experimental studies indicates that, depending on the maturation stage, DCs play a double role in atherogenesis: mature DCs display proatherogenic features whereas immature DCs seem to be anti-atherogenic. In this review, we highlight a double role of DCs in atherogenesis. Obviously, further studies are needed in order to translate knowledge obtained in experiments to human atherogenesis.

\section{SUBSETS AND THEIR ROLE IN ATHEROSCLEROSIS}

There are several subsets of DCs can be distinguished including conventional (myeloid) DCs (cDCs), plasmacytoid DCs (pDCs), and inflammatory DCs (Shortman and Naik, 2007). Inflammatory DCs cannot be found in the steady state but emerge after inflammatory stimuli. Unlike cDCs, pDCs are weak in antigen presentation (Shortman and Naik, 2007). However, pDCs are potent inducers of the interferon (IFN) type I response against viral and bacterial infections (Villadangos and Young, 2008). Choi et al. (2011) have proposed markers to discriminate DCs subsets in murine atherosclerosis but the function of different subsets remains to be elucidated. Although the presence of both subtypes of DCs is known in humans, the most reliable information about the functions of $\mathrm{cDCs}$ and $\mathrm{pDCs}$ are obtained in animal studies (Shortman and Naik, 2007; Villadangos and Young, 2008; Busch et al., 2014).

Normally, vascular DCs were proposed to contribute to maintaining tolerance to self-antigens; in proatherosclerotic conditions, activated vascular DCs may present self-antigens to T cells and promote inflammatory response in the plaque (Niessner and Weyand, 2010). Both pDCs and cDCs were found in the shoulder region of carotid artery lesions (Niessner et al., 2006). pDC were detected in human and mouse atherosclerotic lesions (Niessner et al., 2006; Niessner and Weyand, 2010; Daissormont et al., 2011). pDCs were shown to produce large amount of IFN $\alpha$, a potent regulator of $\mathrm{T}$ cells, that might lead to the unstable plaque phenotype (Niessner et al., 2006). In the LDLR-null mice, pDC depletion, in contrast, led to $\mathrm{T}$ cell accumulation and promoted atherosclerotic lesion formation (Niessner et al., 2006). However, in a recent study, specific depletion of pDC in aortas and spleen of apoE-deficient mice was associated with 
significantly reduced atherosclerosis (Macritchie et al., 2012). In another study, the construction of self-response complexes loaded with patient's DNA and anti-microbial peptides enhanced early plaque formation in apoE-null mice (Döring et al., 2012).

pDS and IFNs isolated from the plaque are involved in the maturation of DCs and macrophages (Döring and Zernecke, 2012). Indeed, these findings suggest for a rather proatherogenic role of pDCs (Döring and Zernecke, 2012) that should be further elucidated. Apart from the existence of cDCs and pDCs, lesion DCs may also arise from the blood-derived monocytes that infiltrate the intima (Randolph et al., 1998). Several studies in mice and humans have addressed this issue (JongstraBilen et al., 2006; Dopheide et al., 2012). Choi et al. (2011) observed in murine aorta new subtype of monocyte-derived DCs $\quad\left(\mathrm{CD}_{11} \mathrm{c}^{\text {high }} \mathrm{MHCII}^{\text {high }} \mathrm{CD} 11 \mathrm{~b}^{-} \mathrm{CD} 103^{+}\right)$. According to Choi et al. (2011), DCs in murine atherosclerosis are primarily presented by two subsets: macrophage-colony stimulating factor (M-CSF)-dependent monocyte-derived DCs

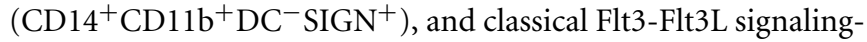

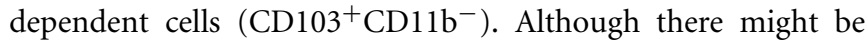
a wide spectrum of DCs subsets in the intima of arteries, the functioning of DCs largely depends on the maturation stage (Butcher and Galkina, 2012).

Immature $\mathrm{CD} 1 \mathrm{a}^{+} \mathrm{S} 100^{+} \mathrm{lag}^{+} \mathrm{CD} 31^{-} \mathrm{CD} 83^{-} \mathrm{CD}^{-} 6^{-}$DCs were found in the normal aortic intima of young individuals (Millonig et al., 2001). HLA-DR ${ }^{+} \mathrm{CDla}^{+} \mathrm{S}-100^{+} \mathrm{DCs}$ were found in the normal human aorta, carotid arteries and in atherosclerotic plaques (Bobryshev and Lord, 1995a; Bobryshev, 2000). DCs are also located in the under-plaque media and in the adventitia around the vasa vasorum in the shoulder regions of the atherosclerotic lesion (Bobryshev and Lord, 1998). Mature CD83 positive DCs were observed in rupture-prone plaque regions in human carotid arteries (Yilmaz et al., 2004). These studies showed that heterogeneity of the DC population seems to increase progressively during the plaque progression.

There are several pathways by which DC numbers can be increased within atherosclerotic plaques. DCs and their precursors could infiltrate plaques migrating from the bloodstream by a chemokine- and adhesion molecule-dependent pathway (Niessner and Weyand, 2010). DCs can migrate to advanced lesions from the adventitia during vasa vasorum-associated neovascularization (Bobryshev and Lord, 1998). The third way is associated with monocytes that penetrate the intima at early atherosclerosis steps in order to differentiate into macrophages or DCs in response to inflammatory stimuli (Randolph et al., 1998). Therefore, inhibition of the activation and recruitment of increasing numbers of activated DCs may be important in preventing lesion formation.

\section{ROLE OF DCs IN INDUCTION OF T-CELL MEDIATED PROINFLAMMATORY RESPONSE IN THE ATHEROSCLEROTIC LESION}

As mentioned above, immature DCs having $\mathrm{CD} 11 \mathrm{c}^{+} \mathrm{CD} 80^{-/ \mathrm{low}} \mathrm{CD} 86^{-/ \text {low }}$ phenotype are tolerogenic DCs responsible for capturing antigens. These DCs might play anti-inflammatory role because they may induce apoptosis or anergy in naïve $\mathrm{T}$ cells responding to self-antigens (Kushwah and $\mathrm{Hu}, 2011)$. By capturing antigens, immature DCs differentiate into mature DCs. Mature CD $11 c^{+} \mathrm{CD} 80^{+} \mathrm{CD} 86^{+} \mathrm{DCs}$, in contrast, may play a proinflammatory role by presenting self-antigens to naïve $\mathrm{T}$ cells, which then differentiate to effector $\mathrm{T}$ cells, and by secreting inflammatory cytokines such as IL-12. During the late stage of monocyte differentiation, oxLDL promote maturating DCs into IL-12-producing cells, which further support inflammatory reaction in the plaque (Perrin-Cocon et al., 2001). Furthermore, in $\mathrm{LDLR}^{-/-}$mice, resident intimal DCs were shown to rapidly accumulate oxLDL and initiate nascent foam cell lesion formation (Paulson et al., 2010). By presenting antigens, mature DCs and macrophages induce adaptive T-cell mediated immune response (Paulson et al., 2010; Choi et al., 2011). However, there is conflicting evidence on the role of oxLDL (and hyperlipidemia) on the maturation and function of DCs (Perrin-Cocon et al., 2001, 2013; Ge et al., 2011; Nickel et al., 2012; Peluso et al., 2012). A recent study by Hermansson et al. (2011) revealed that native LDL can also be recognized by DCs.

In shoulders of human vulnerable atherosclerotic plaques, $\mathrm{CD}^{+}{ }^{+}$DCs were identified in the vicinity to $\mathrm{CD}^{2} \mathrm{~L}^{+} \mathrm{T}$ cells (Yilmaz et al., 2006). This population of DCs secrete CC-motif chemokines (CCL)19 and CCL21 capable to enhance recruitment of naive lymphocytes into atherosclerotic vessels (Erbel et al., 2007) (Figure 2). pDCs responded to pathogen-derived motifs and CpG-containing oligodeoxynucleotides by elevated production of IFN $\alpha$ that recruits naïve $\mathrm{T}$ cells, which then differentiate into cytotoxic $\mathrm{CD} 4^{+}$effector T cells capable to effectively kill vascular smooth muscle cells (VSMCs) (Niessner et al., 2006). Therefore, in the atherosclerotic lesion, pDCs are able to sense microbial motifs and accelerate activity of cytotoxic T-lymphocytes thereby providing a link between severe immunemediated atherosclerotic complications and infections. CD4 ${ }^{+} \mathrm{T}$ cells derived from atherosclerotic plaques are capable to recognize oxLDL, heat shock proteins (HSP)60/65, and other antigens from pathogenic microorganisms such as Chlamydia pneumonia,

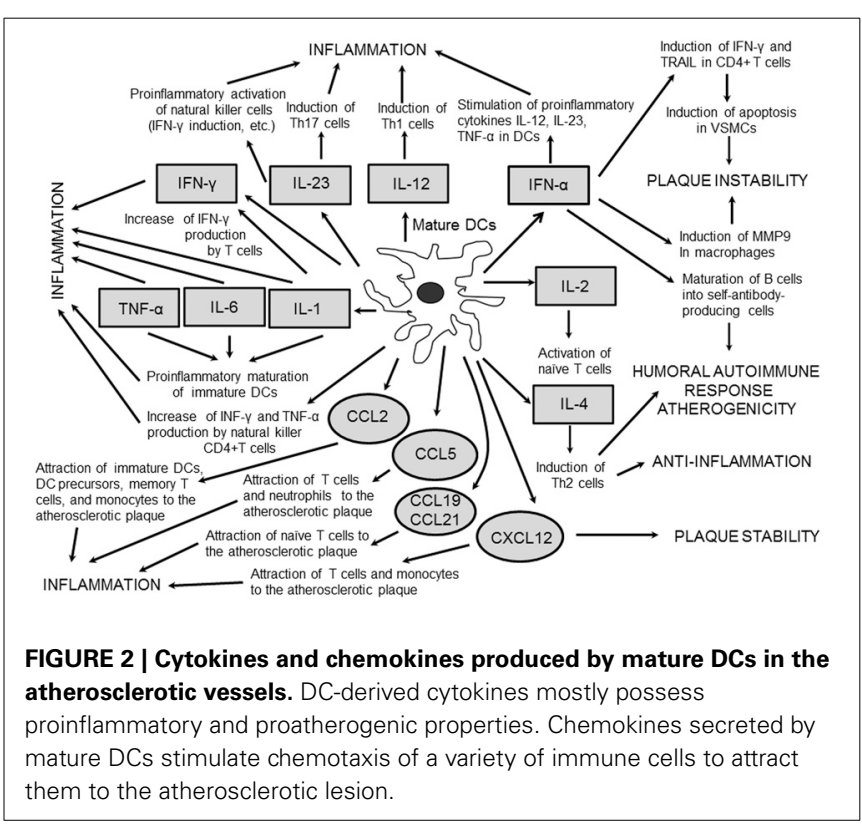


which are supposed to be candidate self-antigens for atherogenesis (Stemme et al., 1995; Benagiano et al., 2005; Mandal et al., 2005). Stephens et al. (2008) showed the ability of a self-peptide Ep1.B derived from human apoE to induce differentiation of monocytes to DCs, thereby suggesting for a putative mechanism of self-antigen-mediated induction of inflammation at early stages of atherosclerosis. Immunochemical staining revealed the presence of C. pneumonia in DCs derived from atherosclerotic plaques thus supporting again a likely role of DCs as a bridge linking the pathogen-induced proinflammatory responses to the induction of atherogenesis (Bobryshev et al., 2004).

\section{CROSSTALKS BETWEEN DCS AND TREGS IN ATHEROSCLEROSIS}

Tregs are involved in the activation, maturation, and function of DCs (Steinman and Banchereau, 2007; Chistiakov et al., 2013). By CTLA-4-dependent inhibition of CD80/CD86 expression in proatherogenic DCs, Tregs are capable to suppress their antigenpresenting activity (Onishi et al., 2008). CTLA-4 is expressed only in stimulated Tregs including forkhead box P3 (Foxp3) ${ }^{+}$ Tregs. Tregs. CTLA-4 interacts with B7-1 (CD80) and B7-2 (CD86) molecules broadly presented in the surface of DCs and macrophages and conducts an inhibitory signal to DCs decreasing expression of both costimulators (Bour-Jordan et al., 2011). Through binding to CD80/CD86, CTLA-4 could initiate production of indoleamine 2,3-dioxigenase (IDO) in DCs. IDO converts tryptophane to kinurenine that is a potent immunosuppressant capable to induce de novo formation of Tregs from naïve T cells in the local environment (Fallarino et al., 2003).

The second inhibitory pathway by which Tregs interacting with mature DCs can down-regulate antigen presentation is CD80/CD86 trogocytosis, which is a process of intercellular transfer of cell surface proteins and outer membrane fragments ( $\mathrm{Gu}$ et al., 2012). Trogocytosis is mediated with CD28, CTLA-4, and programmed death ligand 1 (PDL-1) and involves CD80/CD86 removal from the surface of DCs therefore increasing the inhibitory capacity of Tregs. Tregs from the CTLA-4-knockdown mice failed to suppress CD80/CD86 production suggesting for a key role of CTLA-4 in the suppression of CD80/CD86 expression in antigen-presenting mature DCs (Gao et al., 2011). CTLA-4 binding to CD80/CD86 on the surface of DCs has a major role in inducing tolerance (Oderup et al., 2006). Indeed, CTLA-4 may represent a promising target for treatment of atherosclerosis by enhancing the inhibitory activity of Tregs or increasing suppression of effector T cells (Gotsman et al., 2008).

T-cell adhesion molecule lymphocyte-associated antigen 1 (LFA-1) mediates contact between an antigen-presenting DC and a Treg (Onishi et al., 2008). Tregs maintain the CD80/CD86suppressing capacity even if potent DC-maturating stimuli are present. Thus, Tregs may effectively block proinflammatory signals from antigen-presenting DCs to naive T-lymphocytes via binding to immature DCs followed by CTLA-4/LFA-1-mediated down-regulation of CD80/CD86 production in DCs. Indeed, DCs can influence function of Tregs through their inhibition or stimulation. Proatherosclerotic $\mathrm{CCL} 17^{+} \mathrm{CD} 11^{+}$DCs capable to down-regulate Tregs have been found (Weber et al., 2011). Also, a population of atheroprotective monocyte-derived
$\mathrm{CD}_{11}{ }^{\text {high }} \mathrm{MHC}^{\text {high }} \mathrm{CD} 11 \mathrm{~b}^{-} \mathrm{CD} 103^{+}$DCs which are able to induce Tregs in the lesion was identified (Choi et al., 2011).

Lievens et al. (2013) have constructed an apoE-null mouse harboring a transgene whose expression causes inactivation of tumor factor growth- $\beta$ receptor II (TGF $\beta$ RII)-dependent signaling in CD11-positive DCs. Prevention of TGF $\beta$ RII signaling mechanism results in shifting of $\mathrm{CD} 11 \mathrm{c}^{+} \mathrm{CD} 8^{-}$DCs toward the more proinflammatory $\mathrm{CD}_{11 \mathrm{c}^{+}}$population, which resulted in enhanced $\mathrm{T}$ cell activation and maturation and advanced atherosclerosis. These observations suggest for an anti-atherogenic role of TGF $\beta$ signaling that may be responsible for maintaining immunosupressory properties in DCs and preventing their differentiation toward the proinflammatory phenotype.

Most tolerogenic DCs are immature and have $\mathrm{CD}^{-}{ }^{-} \mathrm{CD}^{-}{ }^{-} \mathrm{CD} 40^{-} \mathrm{MHCII}^{-}$phenotype (Maldonado and von Andrian, 2010). These cells can induce Tregs by direct interaction or through production of cytokines TGF- $\beta$ and IL-10. IL-10 mediates differentiation of peripheral T-cells to Tregs. Tolerogenic DCs producing IL-10 are implicated in the induction of IL-10-producing type 1 regulatory T cells ( $\operatorname{Tr} 1$ ) (Figure 3). Tregs and DCs interact to each other via CCL17 and CCL22, and their receptors, chemokine receptors (CCR) 4 and 8 Iellem et al., 2001; Weber et al., 2011). These receptors are produced on the surface of Tregs and may bind DCs-secreted CCL17 and CCl22. CCL22 induction on tolerogenic CDs results in the recruitment of Tregs in the site of inflammation including the atherosclerotic lesion. The CCR4-deficient mice showed significantly decreased expression of IDO in DCs from mesenteric lymph nodes (Onodera et al., 2009). This finding could suggest for a role of IDO in the regulation of activating effect of CCL22 and CCR4 on Tregs induction. Overall, these observations show that the immunoregulating enzyme IDO has a crucial role in regulating reciprocal DCs-Tregs contacts mediated by B7/CTLA-4 and CCL22/CCR4 in atherogenesis. Therefore, inducing tolerogenic DCs may be important for enhancing protective effects of Trgs against atherosclerosis.

\section{PROGRESS TOWARD THE CLINIC}

In addition to the above suggestion that the development of strategies for the induction of tolerogenic DCs may be of great therapeutic promise, it is important to noting here that the accumulated evidence has showed that, indeed, DCs might be used for anti-atherosclerosis immunotherapy. The support for this view has come from a number of studies performed on mouse models of atherosclerosis in which the function of DCs was manipulated (Zhou et al., 2006; Hjerpe et al., 2010; Daissormont et al., 2011; de Jager and Kuiper, 2011; Döring et al., 2012; Macritchie et al., 2012). Currently, there is no sufficient evidence to state that $\mathrm{CDCs}$ are proatherogenic and that $\mathrm{pDCs}$ are atheroprotective. Nevertheless, based on the assumption that cDCs action is rather proatherogenic whereas pDCs might be atheroprotective, the inhibition of cDCs can induce atheroprotective immune reactions (Bobryshev, 2010).

DCs are thought nowadays as a valuable instrument for atherosclerosis immunotherapy (Van Vré et al., 2011; Takeda et al., 2012; Grassia et al., 2013; Van Brussel et al., 2013, 2014). DCs could also induce tolerance against antigens that are innate 


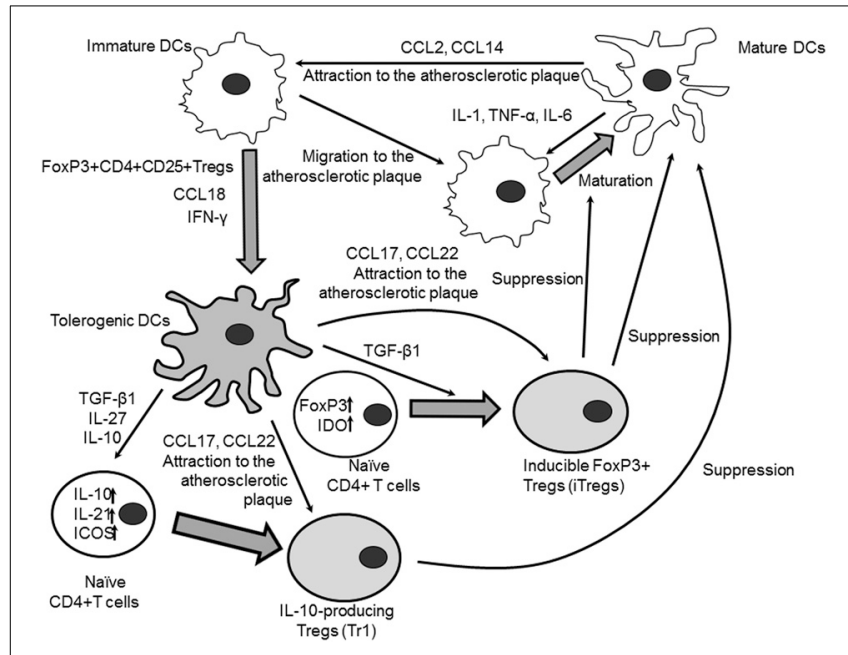

FIGURE 3 | Crosstalk between immature and mature DCs. Mature DCs could attract immature DCs and DC precursors to the site of inflammation (i.e., to the atherosclerotic plaque) through secretion of chemokines CCL2 and CCL14. Immature DCs in turn migrate to the plaque where they are activated by the local proinflammatory microenvironment to differentiate preferentially to inflammatory mature antigen-presenting DCs. Local mature DCs could contribute to the proinflammatory DC maturation by secreting inflammatory cytokines IL-1 $\beta$, IL-6, and TNF- $\alpha$. Natural FoxP3 ${ }^{+} \mathrm{CD} 4^{+} \mathrm{CD} 25^{+}$ $T$ cells induce conversion of immature DCs to tolerogenic DCs. Chemokine CCL18 produced by immature DCs stimulates tolerogenicity through the induction of IL-10-mediated expression of IDO in DCs. IFN- $\gamma$ is able to contribute to the formation of tolerogenic DCs by inhibiting expression of Th17-inducing osteoprotegerin and stimulating IL-27 production. IL-27 suppresses production of Th17-polarizing cytokines IL-1 $\beta, I L-6$, and IL-23 from DCs and activates expression of IL-10, IL-21, and ICOS in naïve CD4 ${ }^{+} T$ cells that drives induction of IL-10 producing Tregs (Tr 1 ). IL-10 produced by tolerogenic DCs induces Tr1 cells through the ILT2/ILT4-mediated signaling mechanism. TGF- $\beta 1$ secreted by tolerogenic DCs could induce expression of FoxP3 and IDO in $\mathrm{CD}^{+}{ }^{+} \mathrm{CD} 25^{-}$naive T cells that promotes their conversion into inducible FoxP3 ${ }^{+}$Tregs (iTregs). Chemokines CCL17 and CCL22 secreted by tolerogenic CDs attract Tregs to the atherosclerotic lesion where Tregs could suppress immunomodulatory properties of proinflammatory antigen-presenting CDs and prevent differentiation of immature CDs to inflammatory subsets of mature DCs.

to the body (Steinman et al., 2003; Palucka and Banchereau, 2012). DCs can be used as natural adjuvants for the induction of antigen-specific T-cell responses (Caminschi et al., 2012; Palucka and Banchereau, 2012; Yamanaka and Kajiwara, 2012). Antiatherosclerotic immunotherapy with the utilization of DCs may be the same or somewhat different from those approaches that are currently used for cancer immunotherapy (Caminschi et al., 2012; Palucka and Banchereau, 2012; Yamanaka and Kajiwara, 2012). It is essential to stress that remarkable results have been achieved in treatment of cancer patients when DCs loaded with an antigen were used as vaccines for improving the host anti-cancer immune response (Palucka and Banchereau, 2012; Yamanaka and Kajiwara, 2012). One of approaches involves an ex vivo treatment of DCs with an appropriate antigen, followed by further return of the antigen-treated DCs (so called "pulsed" DCs) back to the patient' blood. A similar approach can be evaluated for the use in atherosclerosis immunotherapy (Bobryshev, 2001).
One of the main challenges for developing of effective vaccines for atherosclerosis relates to the selection of a specific antigen to target. Several strategies have been offered; So far, vaccination strategies have been based on targeting of lipid antigens and inflammation-derived antigens (de Jager and Kuiper, 2011). Amongst the used approaches, immunization of hypercholesterolemic animals with oxLDL or specific epitopes of ApoB100 has been reported to inhibit atherosclerosis (Nilsson et al., 2007; van Leeuwen et al., 2009). Perhaps, DCs pulsed with autologous modified LDL or immunogenic components of autologous modified LDL could be used as well for immunization; this would allow avoiding side effects of direct vaccination with oxLDL (Bobryshev, 2010). Apart from pulsation with modified LDL, DCs can be also treated ex vivo through culturing with a total extract of the "own" atherosclerotic lesion, for instance, from subjects who underwent carotid enadarterectomy or other vascular interventions (Bobryshev, 2001). An obvious advantage of such approach, in which a patient is vaccinated with its "own" DCs pulsed by patient's "own" antigens is the specificity: the event of pulsation of DCs would mimic the processes that occur in plaques of the patient. This approach can be considered as an example of "personalized" medicine (Hamburg and Collins, 2010).

Although the idea to use of DCs for vaccination in atherosclerosis is widely discussed (de Jager and Kuiper, 2011; Van Vré et al., 2011; Cheong and Choi, 2012; Döring and Zernecke, 2012; Takeda et al., 2012; Van Brussel et al., 2013, 2014), experimental studies that already utilized DCs for immunotherapy of atherosclerosis are still quite limited (Habets et al., 2010; Hjerpe et al., 2010; van Es et al., 2010; Hermansson et al., 2011; Pierides et al., 2013). Currently, an immunotherapeutic strategy based on the isolation of autologous DCs, subsequent loading with appropriate antigen(s) ex vivo (e.g., immunogenic epitopes of modified LDL or a total plaque extract), and return to the host blood is under development (Habets et al., 2010; Hjerpe et al., 2010; van Es et al., 2010; Hermansson et al., 2011; Pierides et al., 2013) (Table 1). The future of this strategy is consisted in the development of atheroprotective vaccines on the basis of patient's DCs (Van Brussel et al., 2013).

Another promising strategy involves studying properties of various immune cells interacting with DCs in order to develop DCs-based vaccines capable to modulate those immune cells in atherosclerosis. For example, van Es et al. (2010) used DCs expressing a FoxP3 transgene, a master regulator in the development and function of Tregs, to induce the anti-FoxP3 immune response in LDLR-null mice. The anti-FoxP3-specific immunity resulted in partial depletion of FoxP3-positive Tregs in several organs, early induction of proatherogenic inflammation and advanced atherosclerotic plaque progression. This observation indeed suggests for the crucial atheroprotective properties of Tregs.

An adoptive transfer of natural killer $\mathrm{T}$ (NKT) cells from $\mathrm{V} \alpha 14 \mathrm{~J} \alpha 18 \mathrm{~T}$-cell receptor transgenic mice caused significant progression in aortic atherosclerosis in recipient immune-deficient RAG-null LDLR-null mice (VanderLaan et al., 2007). Serum derived from the recipient animals then induced activation of V $\alpha 14 \mathrm{~J} \alpha 18$ T-cell receptor-expressing hybridoma by DCs. This finding shows proatherogenic properties of CD1d-dependent 
Table 1 | Examples of anti-atherosclerosis immunization of experimental atherosclerosis animal models involving LDL or its related peptides.

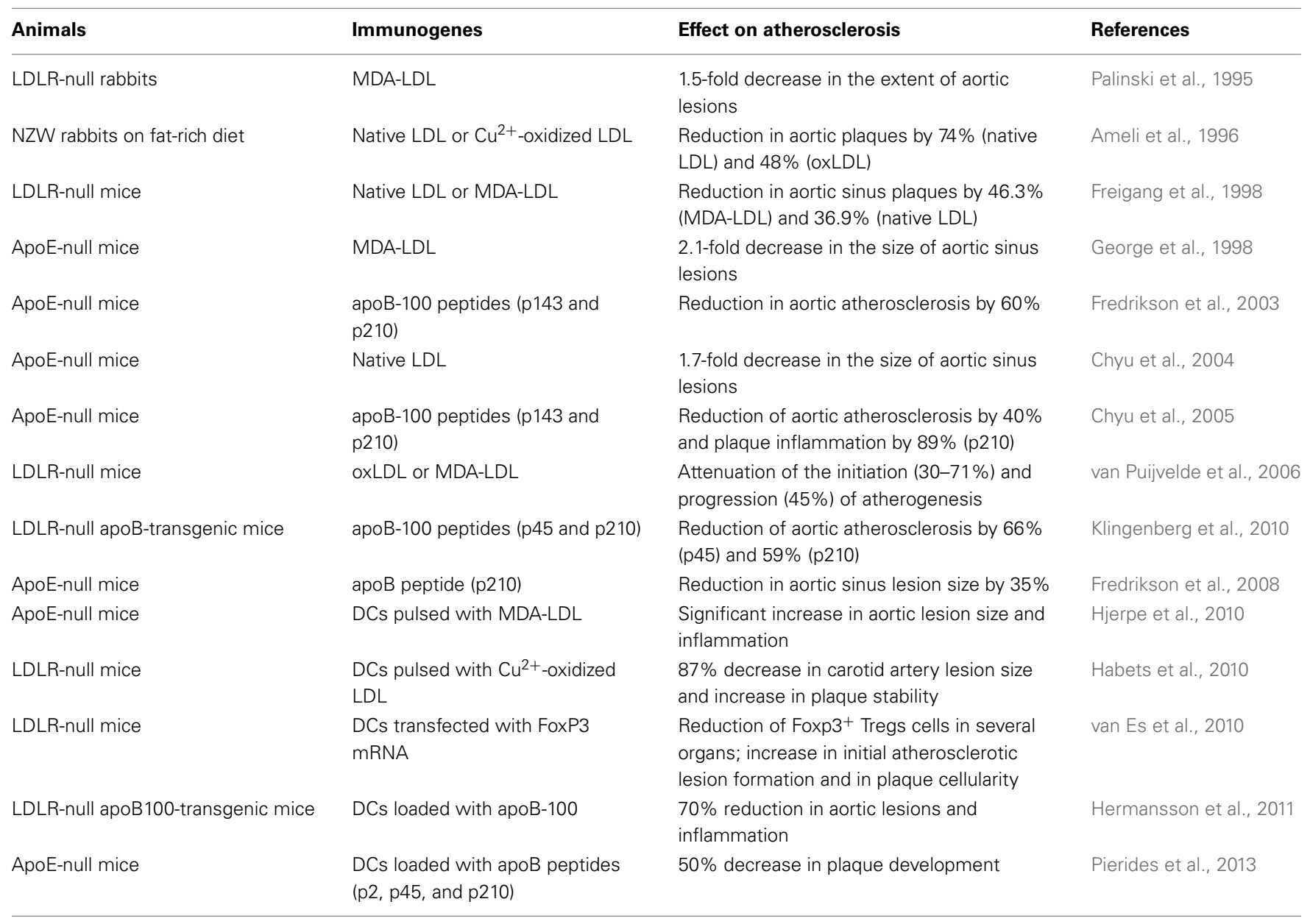

apo, apolipoprotein; FoxP3, forkhead box P3; LDL, low density lipoprotein; LDLR, LDL receptor; MDA-LDL, malonaldehyde-modified LDL; NZW, New Zealand White; oxLDL, oxidized $L D L ;$ Tregs, regulatory $T$ cells.

V $\alpha 14$ subpopulation of NKT cells that were likely to be stimulated by circulating endogenic lipoproteins in the atherosclerosis-prone animals (Rogers et al., 2008). Thus, such an approach may offer a tool for dissecting the contributions of individual subpopulations of particular immune cells to the process of atherogenesis. In the future, developing immune vaccines on the basis of specific subsets of DCs should be helpful for selective depletion of deleterious proatherogenic populations of effector cells such as Th1 and Th17 cells and induction of immunosuppressive anti-inflammatory Tregs (Van Brussel et al., 2013).

\section{CONCLUDING REMARKS}

It is appreciated nowadays that atherosclerosis is a chronic destruction of aortic and arterial walls, with a marked involvement of inflammation (Hansson and Hermansson, 2011; Tuttolomondo et al., 2012). DCs are recognized as key players in the induction of inflammatory response in the atherosclerotic plaque. It has become known that $\mathrm{T}$ cell activation occurs after a cell-to-cell-contact between a DC and a naïve $\mathrm{T}$ cells and by stimulation of the proinflammatory cytokines secreted by mature DCs. A proinflammatory function of mature DCs may be suppressed by a special subclass of $\mathrm{T}$ cells, namely by Tregs. On the other hand, immature DCs possess tolerogenic antiinflammatory properties by leading naive $\mathrm{T}$ cells to anergy or apoptosis and by inducing Tregs. Thus, depending on the maturation stage, DCs play a double role in atherogenesis: mature DCs display proatherogenic features whereas immature DCs seem to be anti-atherogenic. Since immature DCs are capable to induce Tregs and inhibit the inflammatory reaction in the atherosclerotic lesion, the development of strategies for the induction of tolerogenic DCs may be of great therapeutic promise.

\section{ACKNOWLEDGMENT}

We wish to thank the Russian Ministry of Education and Science and the School of Medical Sciences, University of New south Wales, Sydney, Australia, for support of our work.

\section{REFERENCES}

Alberts-Grill, N., Denning, T. L., Rezvan, A., and Jo, H. (2013). The role of the vascular dendritic cell network in atherosclerosis. Am. J. Physiol. Cell. Physiol. 305, C1-C21. doi: 10.1152/ajpcell.00017.2013

Ameli, S., Hultgårdh-Nilsson, A., Regnström, J., Calara, F., Yano, J., Cercek, B., et al. (1996). Effect of immunization with homologous LDL and oxidized LDL on 
early atherosclerosis in hypercholesterolemic rabbits. Arterioscler. Thromb. Vasc. Biol. 16, 1074-1079. doi: 10.1161/01.ATV.16.8.1074

Benagiano, M., D'Elios, M. M., Amedei, A., Azzurri, A., van der Zee, R., Ciervo, A., et al. (2005). Human $60-\mathrm{kDa}$ heat shock protein is a target autoantigen of $\mathrm{T}$ cells derived from atherosclerotic plaques. J. Immunol. 174, 6509-6517. doi: 10.4049/jimmunol.174.10.6509

Bobryshev, Y. V. (2000). Dendritic cells and their involvement in atherosclerosis. Curr. Opin. Lipidol. 11, 511-517. doi: 10.1097/00041433-200010000-00009

Bobryshev, Y. V. (2001). Can dendritic cells be exploited for therapeutic intervention in atherosclerosis? Atherosclerosis 154, 511-512. doi: 10.1016/S00219150(00)00692-4

Bobryshev, Y. V. (2005). Dendritic cells in atherosclerosis: current status of the problem and clinical relevance. Eur. Heart J. 26, 1700-1704. doi: 10.1093/eurheartj/ehi282

Bobryshev, Y. V. (2010). Dendritic cells and their role in atherogenesis. Lab. Invest. 90, 970-984. doi: 10.1038/labinvest.2010.94

Bobryshev, Y. V., Babaev, V. R., Lord, R. S., and Watanabe, T. (1999). Ultrastructural identification of cells with dendritic cell appearance in atherosclerotic aorta of apolipoprotein E deficient mice. J. Submicrosc. Cytol. Pathol. 31, 527-531.

Bobryshev, Y. V., Cao, W., Phoon, M. C., Tran, D., Chow, V. T., Lord, R. S., et al. (2004). Detection of Chlamydophila pneumoniae in dendritic cells in atherosclerotic lesions. Atherosclerosis 173, 185-195. doi: 10.1016/j.atherosclerosis. 2003.12.028

Bobryshev, Y. V., and Lord, R. S. (1995a). Ultrastructural recognition of cells with dendritic cell morphology in human aortic intima. Contacting interactions of Vascular Dendritic Cells in athero-resistant and athero-prone areas of the normal aorta. Arch. Histol. Cytol. 58, 307-322. doi: 10.1679/aohc.58.307

Bobryshev, Y. V., and Lord, R. S. (1995b). S-100 positive cells in human arterial intima and in atherosclerotic lesions. Cardiovasc. Res. 29, 689-696. doi: 10.1016/0008-6363(96)88642-1

Bobryshev, Y. V., and Lord, R. S. (1998). Mapping of vascular dendritic cells in atherosclerotic arteries suggests their involvement in local immuneinflammatory reactions. Cardiovasc. Res. 37, 799-810. doi: 10.1016/S00086363(97)00229-0

Bobryshev, Y. V., Moisenovich, M. M., Pustovalova, O. L., Agapov, I. I., and Orekhov, A. N. (2012). Widespread distribution of HLA-DR-expressing cells in macroscopically undiseased intima of the human aorta: a possible role in surveillance and maintenance of vascular homeostasis. Immunobiology 217 558-568. doi: 10.1016/j.imbio.2011.03.014

Bobryshev, Y. V., Taksir, T., Lord, R. S., and Freeman, M. W. (2001). Evidence that dendritic cells infiltrate atherosclerotic lesions in apolipoprotein E-deficient mice. Histol. Histopathol. 16, 801-808.

Bour-Jordan, H., Esensten, J. H., Martinez-Llordella, M., Penaranda, C., Stumpf, M., and Bluestone, J. A. (2011). Intrinsic and extrinsic control of peripheral Tcell tolerance by costimulatory molecules of the CD28/B7 family. Immunol. Rev. 241, 180-205. doi: 10.1111/j.1600-065X.2011.01011.x

Busch, M., Westhofen, T. C., Koch, M., Lutz, M. B., and Zernecke, A. (2014). Dendritic cell subset distributions in the aorta in healthy and atherosclerotic mice. PLOS ONE 9:e88452. doi: 10.1371/journal.pone.0088452

Butcher, M. J., and Galkina, E. V. (2012). Phenotypic and functional heterogeneity of macrophages and dendritic cell subsets in the healthy and atherosclerosisprone aorta. Front. Physiol. 3:44. doi: 10.3389/fphys.2012.00044

Caminschi, I., Maraskovsky, E., and Heath, W. R. (2012). Targeting dendritic cells in vivo for cancer therapy. Front. Immunol. 3:13. doi: 10.3389/fimmu.2012.00013

Cartland, S. P., and Jessup, W. (2013). Dendritic cells in atherosclerosis. Curr. Pharm. Des. 19, 5883-5890. doi: 10.2174/1381612811319330007

Cheong, C., and Choi, J. H. (2012). Dendritic cells and regulatory T cells in atherosclerosis. Mol. Cells 34, 341-347. doi: 10.1007/s10059-012-0128-9

Chistiakov, D. A., Sobenin, I. A., and Orekhov, A. N. (2013). Regulatory T cells in atherosclerosis and strategies to induce the endogenous atheroprotective immune response. Immunol. Lett. 151, 10-22. doi: 10.1016/j.imlet.2013.01.014

Choi, J. H., Cheong, C., Dandamudi, D. B., Park, C. G., Rodriguez, A., Mehandru, S., et al. (2011). Flt3 signaling-dependent dendritic cells protect against atherosclerosis. Immunity 35, 819-831. doi: 10.1016/j.immuni.2011.09.014

Chyu, K. Y., Reyes, O. S., Zhao, X., Yano, J., Dimayuga, P., Nilsson, J., et al. (2004). Timing affects the efficacy of LDL immunization on atherosclerotic lesions in apo E (-/-) mice. Atherosclerosis 176, 27-35. doi: 10.1016/j.atherosclerosis.2004.04.016
Chyu, K. Y., Zhao, X., Reyes, O. S., Babbidge, S. M., Dimayuga, P. C., Yano, J., et al. (2005). Immunization using an Apo B-100 related epitope reduces atherosclerosis and plaque inflammation in hypercholesterolemic apo $\mathrm{E}(-/-)$ mice. Biochem. Biophys. Res. Commun. 338, 1982-1989. doi: 10.1016/j.bbrc.2005.10.141

Cocks, B. G., Chang, C. C., Carballido, J. M., Yssel, H., de Vries, J. E., and Aversa, G. (1995). A novel receptor involved in T-cell activation. Nature 376, 260-263. doi: $10.1038 / 376260 \mathrm{a} 0$

Cybulsky, M. I., and Jongstra-Bilen, J. (2010). Resident intimal dendritic cells and the initiation of atherosclerosis.Curr. Opin. Lipidol. 21, 397-403. doi: 10.1097/MOL.0b013e32833ded96

Daissormont, I. T., Christ, A., Temmerman, L., Sampedro Millares, S., Seijkens, T., Manca, M., et al. (2011). Plasmacytoid dendritic cells protect against atherosclerosis by tuning T-cell proliferation and activity. Circ. Res. 109, 1387-1395. doi: 10.1161/CIRCRESAHA.111.256529

de Jager, S. C., and Kuiper, J. (2011). Vaccination strategies in atherosclerosis. Thromb. Haemost. 106, 796-803. doi: 10.1160/TH11-05-0369

Dopheide, J. F., Obst, V., Doppler, C., Radmacher, M. C., Scheer, M., Radsak, M. P., et al. (2012). Phenotypic characterisation of pro-inflammatory monocytes and dendritic cells in peripheral arterial disease. Thromb. Haemost. 108, 1198-1207. doi: 10.1160/TH12-05-0327

Döring, Y., Manthey, H. D., Drechsler, M., Lievens, D., Megens, R. T., Soehnlein, O., et al. (2012). Auto-antigenic protein-DNA complexes stimulate plasmacytoid dendritic cells to promote atherosclerosis. Circulation 125, 1673-1683. doi: 10.1161/CIRCULATIONAHA.111.046755

Döring, Y., and Zernecke, A. (2012). Plasmacytoid dendritic cells in atherosclerosis. Front. Physiol. 3:230. doi: 10.3389/fphys.2012.00230

Erbel, C., Sato, K., Meyer, F. B., Kopecky, S. L., Frye, R. L., Goronzy, J. J., et al. (2007). Functional profile of activated dendritic cells in unstable atherosclerotic plaque. Basic Res. Cardiol. 102, 123-132. doi: 10.1007/s00395-006-0636-x

Fallarino, F., Grohmann, U., Hwang, K. W., Orabona, C., Vacca, C., Bianchi, R., et al. (2003). Modulation of tryptophan catabolism by regulatory T cells. Nat. Immunol. 4, 1206-1212. doi: 10.1038/ni1003

Feig, J. E., and Feig, J. L. (2012). Macrophages, dendritic cells, and regression of atherosclerosis. Front. Physiol. 3:286. doi: 10.3389/fphys.2012.00286

Fredrikson, G. N., Björkbacka, H., Söderberg, I., Ljungcrantz, I., and Nilsson, J. (2008). Treatment with apo B peptide vaccines inhibits atherosclerosis in human apo B-100 transgenic mice without inducing an increase in peptide-specific antibodies. J. Intern. Med. 264, 563-570. doi: 10.1111/j.1365-2796.2008.01995.x

Fredrikson, G. N., Söderberg, I., Lindholm, M., Dimayuga, P., Chyu, K. Y., Shah, P. K., et al. (2003). Inhibition of atherosclerosis in apoE-null mice by immunization with apoB-100 peptide sequences. Arterioscler. Thromb. Vasc. Biol. 23, 879-884. doi: 10.1161/01.ATV.0000067937.93716.DB

Freigang, S., Hörkkö, S., Miller, E., Witztum, J. L., and Palinski, W. (1998). Immunization of LDL receptor-deficient mice with homologous malondialdehyde-modified and native LDL reduces progression of atherosclerosis by mechanisms other than induction of high titers of antibodies to oxidative neoepitopes. Arterioscler. Thromb. Vasc. Biol. 18, 1972-1982. doi: 10.1161/01.ATV.18.12.1972

Gao, J. F., McIntyre, M. S., Juvet, S. C., Diao, J., Li, X., Vanama, R. B., et al. (2011). Regulation of antigen-expressing dendritic cells by double negative regulatory $\mathrm{T}$ cells. Eur. J. Immunol. 41, 2699-2708. doi: 10.1002/eji.201141428

Ge, J., Yan, H., Li, S., Nie, W., Dong, K., Zhang, L., et al. (2011). Changes in proteomics profile during maturation of marrow-derived dendritic cells treated with oxidized low-density lipoprotein. Proteomics 11, 1893-1902. doi: 10.1002/pmic. 201000658

George, J., Afek, A., Gilburd, B., Levkovitz, H., Shaish, A., Goldberg, I., et al. (1998). Hyperimmunization of apo-E-deficient mice with homologous malondialdehyde low-density lipoprotein suppresses early atherogenesis. Atherosclerosis 138 , 147-152. doi: 10.1016/S0021-9150(98)00015-X

Gotsman, I., Sharpe, A. H., and Lichtman, A. H. (2008). T-cell costimulation and coinhibition in atherosclerosis. Circ. Res. 103, 1220-1231. doi: 10.1161/CIRCRESAHA.108.182428

Grassia, G., Macritchie, N., Platt, A. M., Brewer, J. M., Garside, P., and Maffia, P. (2013). Plasmacytoid dendritic cells: Biomarkers or potential therapeutic targets in atherosclerosis? Pharmacol. Ther. 137, 172-182. doi: 10.1016/j.pharmthera.2012.10.001

Gu, P., Gao, J. F., D'Souza, C. A., Kowalczyk, A., Chou, K. Y., and Zhang, L. (2012). Trogocytosis of CD80 and CD86 by induced regulatory T cells. Cell. Mol. Immunol. 9, 136-146. doi: 10.1038/cmi.2011.62 
Habets, K. L., van Puijvelde, G. H., van Duivenvoorde, L. M., van Wanrooij, E. J., de Vos, P., Tervaert, J. W., et al. (2010). Vaccination using oxidized low-density lipoprotein-pulsed dendritic cells reduces atherosclerosis in LDL receptor-deficient mice. Cardiovasc. Res. 85, 622-630. doi: 10.1093/cvr/cvp338

Hamburg, M. A., and Collins, F. S. (2010). The path to personalized medicine. N. Engl. J. Med. 363, 301-304. doi: 10.1056/NEJMp1006304

Hansson, G. K., and Hermansson, A. (2011). The immune system in atherosclerosis. Nat. Immunol. 12, 204-212. doi: 10.1038/ni.2001

Hermansson, A., Johansson, D. K., Ketelhuth, D. F., Andersson, J., Zhou, X., and Hansson, G. K. (2011). Immunotherapy with tolerogenic apolipoprotein B100-loaded dendritic cells attenuates atherosclerosis in hypercholesterolemic mice. Circulation 123, 1083-1091. doi: 10.1161/CIRCULATIONAHA.110. 973222

Hjerpe, C., Johansson, D., Hermansson, A., Hansson, G. K., and Zhou, X. (2010). Dendritic cells pulsed with malondialdehyde modified low density lipoprotein aggravate atherosclerosis in Apoe(-/-) mice. Atherosclerosis 209, 436-441. doi 10.1016/j.atherosclerosis.2009.10.003

Iellem, A., Mariani, M., Lang, R., Recalde, H., Panina-Bordignon, P., Sinigaglia, F., et al. (2001). Unique chemotactic response profile and specific expression of chemokine receptors CCR4 and CCR8 by CD4(+)CD25(+) regulatory T cells. J. Exp. Med. 194, 847-853. doi: 10.1084/jem.194.6.847

Jongstra-Bilen, J., Haidari, M., Zhu, S. N., Chen, M., Guha, D., and Cybulsky, M. I. (2006). Low-grade chronic inflammation in regions of the normal mouse arterial intima predisposed to atherosclerosis. J. Exp. Med. 203, 2073-2083. doi: 10.1084/jem.20060245

Klingenberg, R., Lebens, M., Hermansson, A., Fredrikson, G. N., Strodthoff, D., Rudling, M., et al. (2010). Intranasal immunization with an apolipoprotein B-100 fusion protein induces antigen-specific regulatory $\mathrm{T}$ cells and reduces atherosclerosis. Arterioscler. Thromb. Vasc. Biol. 30, 946-952. doi: 10.1161/ATVBAHA.109.202671

Koltsova, E. K., Hedrick, C. C., and Ley, K. (2013). Myeloid cells in atherosclerosis: a delicate balance of anti-inflammatory and proinflammatory mechanisms. Curr. Opin. Lipidol. 24, 371-380. doi: 10.1097/MOL.0b013e328363d298

Koltsova, E. K., and Ley, K. (2011). How dendritic cells shape atherosclerosis. Trends Immunol. 32, 540-547. doi: 10.1016/j.it.2011.07.001

Kubin, M., Kamoun, M., and Trinchieri, G. (1994). Interleukin 12 synergizes with B7/CD28 interaction in inducing efficient proliferation and cytokine production of human T cells. J. Exp. Med. 180, 211-222. doi: 10.1084/jem.180.1.211

Kushwah, R., and Hu, J. (2011). Role of dendritic cells in the induction of regulatory T cells. Cell. Biosci. 1, 20. doi: 10.1186/2045-3701-1-20

Lievens, D., Habets, K. L., Robertson, A. K., Laouar, Y., Winkels, H., Rademakers, T., et al. (2013). Abrogated transforming growth factor beta receptor II (TGF $\beta$ RII) signalling in dendritic cells promotes immune reactivity of $\mathrm{T}$ cells resulting in enhanced atherosclerosis. Eur. Heart. J. 34, 3717-3727. doi: 10.1093/eurheartj/ehs106

Ludewig, B., Freigang, S., Jäggi, M., Kurrer, M. O., Pei, Y. C., Vlk, L., et al. (2000). Linking immune-mediated arterial inflammation and cholesterolinduced atherosclerosis in a transgenic mouse model. Proc. Natl. Acad. Sci. U.S.A. 97, 12752-12757. doi: 10.1073/pnas.220427097

Macritchie, N., Grassia, G., Sabir, S. R., Maddaluno, M., Welsh, P., Sattar, N., et al. (2012). Plasmacytoid dendritic cells play a key role in promoting atherosclerosis in apolipoprotein e-deficient mice. Arterioscler. Thromb. Vasc. Biol. 32, 2569-2579. doi: 10.1161/ATVBAHA.112.251314

Maldonado, R. A., and von Andrian, U. H. (2010). How tolerogenic dendritic cells induce regulatory T cells. Adv. Immunol. 108, 111-165. doi: 10.1016/B978-0-12380995-7.00004-5

Mandal, K., Jahangiri, M., and Xu, Q. (2005). Autoimmune mechanisms of atherosclerosis. Handb. Exp. Pharmacol. 170, 723-743. doi: 10.1007/3-54027661-0_27

Manthey, H. D., and Zernecke, A. (2011). Dendritic cells in atherosclerosis: functions in immune regulation and beyond. Thromb. Haemost. 106, 772-778. doi: 10.1160/TH11-05-0296

Millonig, G., Niederegger, H., Rabl, W., Hochleitner, B. W., Hoefer, D., Romani, N., et al. (2001). Network of vascular-associated dendritic cells in intima of healthy young individuals. Arterioscler. Thromb. Vasc. Biol. 21, 503-508. doi: 10.1161/01.ATV.21.4.503

Nickel, T., Pfeiler, S., Summo, C., Kopp, R., Meimarakis, G., Sicic, Z., et al. (2012). oxLDL downregulates the dendritic cell homing factors CCR7 and CCL21. Mediators Inflamm. 2012:320953. doi: 10.1155/2012/320953
Niessner, A., Sato, K., Chaikof, E. L., Colmegna, I., Goronzy, J. J., and Weyand, C. M. (2006). Pathogen-sensing plasmacytoid dendritic cells stimulate cytotoxic T-cell function in the atherosclerotic plaque through interferonalpha. Circulation 114, 2482-2489. doi: 10.1161/CIRCULATIONAHA.106.6 42801

Niessner, A., and Weyand, C. M. (2010). Dendritic cells in atherosclerotic disease. Clin. Immunol. 134, 25-32. doi: 10.1016/j.clim.2009.05.006

Nilsson, J., Nordin Fredrikson, G., Schiopu, A., Shah, P. K., Jansson, B., and Carlsson, R. (2007). Oxidized LDL antibodies in treatment and risk assessment of atherosclerosis and associated cardiovascular disease. Curr. Pharm. Des. 13, 1021-1030. doi: 10.2174/138161207780487557

Oderup, C., Cederbom, L., Makowska, A., Cilio, C. M., and Ivars, F. (2006). Cytotoxic T lymphocyte antigen-4-dependent down-modulation of costimulatory molecules on dendritic cells in CD4+ CD25+ regulatory T-cell-mediated suppression. Immunology 118, 240-249. doi: 10.1111/j.1365-2567.2006. 02362.x

Onishi, Y., Fehervari, Z., Yamaguchi, T., and Sakaguchi, S. (2008). Foxp3+ natural regulatory $\mathrm{T}$ cells preferentially form aggregates on dendritic cells in vitro and actively inhibit their maturation. Proc. Natl. Acad. Sci. U.S.A. 105, 10113-10118. doi: 10.1073/pnas.0711106105

Onodera, T., Jang, M. H., Guo, Z., Yamasaki, M., Hirata, T., Bai, Z., et al. (2009) Constitutive expression of IDO by dendritic cells of mesenteric lymph nodes: functional involvement of the CTLA-4/B7 and CCL22/CCR4 interactions. J. Immunol. 183, 5608-5614. doi: 10.4049/jimmunol.0804116

Palinski, W., Miller, E., and Witztum, J. L. (1995). Immunization of low density lipoprotein (LDL) receptor-deficient rabbits with homologous malondialdehyde-modified LDL reduces atherogenesis. Proc. Natl. Acad. Sci. U.S.A. 92, 821-825. doi: 10.1073/pnas.92.3.821

Palucka, K., and Banchereau, J. (2012). Cancer immunotherapy via dendritic cells. Nat. Rev. Cancer 12, 265-277. doi: 10.1038/nrc3258

Paulson, K. E., Zhu, S. N., Chen, M., Nurmohamed, S., Jongstra-Bilen, J., and Cybulsky, M. I. (2010). Resident intimal dendritic cells accumulate lipid and contribute to the initiation of atherosclerosis. Circ. Res. 106, 383-390. doi: 10.1161/CIRCRESAHA.109.210781

Peluso, I., Morabito, G., Urban, L., Ioannone, F., and Serafini, M. (2012). Oxidative stress in atherosclerosis development: the central role of LDL and oxidative burst. Endocr. Metab. Immune Disord. Drug. Targets 12, 351-360. doi: $10.2174 / 187153012803832602$

Perrin-Cocon, L., Coutant, F., Agaugué, S., Deforges, S., André, P., and Lotteau, V. (2001). Oxidized low-density lipoprotein promotes mature dendritic cell transition from differentiating monocyte. J. Immunol. 167, 3785-3791. doi: 10.4049/jimmunol.167.7.3785

Perrin-Cocon, L., Diaz, O., André, P., and Lotteau V. (2013). Modified lipoproteins provide lipids that modulate dendritic cell immune function. Biochimie 95, 103-108. doi: 10.1016/j.biochi.2012.08.006

Pierides, C., Bermudez-Fajardo, A., Fredrikson, G. N., Nilsson, J., and Oviedo-Orta, E. (2013). Immune responses elicited by apoB-100-derived peptides in mice. Immunol. Res. 56, 96-108. doi: 10.1007/s12026-0138383-1

Randolph, G. J., Beaulieu, S., Lebecque, S., Steinman, R. M., and Muller W. A. (1998). Differentiation of monocytes into dendritic cells in a model of transendothelial trafficking. Science 282, 480-483. doi: 10.1126/science. 282.5388 .480

Rogers, L., Burchat, S., Gage, J., Hasu, M., Thabet, M., Willcox, L., et al. (2008). Deficiency of invariant V alpha 14 natural killer T cells decreases atherosclerosis in LDL receptor null mice. Cardiovasc. Res. 78, 167-174. doi: $10.1093 / \mathrm{cvr} / \mathrm{cvn} 005$

Shortman, K., and Naik, S. H. (2007). Steady-state and inflammatory dendritic-cell development. Nat. Rev. Immunol. 7, 19-30. doi: 10.1038/nri1996

Sorg, R. V., Kögler, G., and Wernet, P. (1999). Identification of cord blood dendritic cells as an immature CD11c- population. Blood 93, 2302-2307.

Steinman, R. M., and Banchereau, J. (2007). Taking dendritic cells into medicine. Nature 449, 419-426. doi: 10.1038/nature06175

Steinman, R. M., and Cohn, Z. A. (1973). Identification of a novel cell type in peripheral lymphoid organs of mice. I. Morphology, quantitation, tissue distribution. J. Exp. Med. 137, 1142-1162. doi: 10.1084/jem.137.5.1142

Steinman, R. M., Hawiger, D., and Nussenzweig, M. C. (2003). Tolerogenic dendritic cells. Annu. Rev. Immunol. 21, 685-711. doi: 10.1146/annurev.immunol.21.120601.141040 
Stemme, S., Faber, B., Holm, J., Wiklund, O., Witztum, J. L., and Hansson, G. K. (1995). T lymphocytes from human atherosclerotic plaques recognize oxidized low density lipoprotein. Proc. Natl. Acad. Sci. U.S.A. 92, 3893-3897. doi: 10.1073/pnas.92.9.3893

Stephens, T. A., Nikoopour, E., Rider, B. J., Leon-Ponte, M., Chau, T. A., Mikolajczak, S., et al. (2008). Dendritic cell differentiation induced by a selfpeptide derived from apolipoprotein E. J. Immunol. 181, 6859-6871. doi: 10.4049/jimmunol.181.10.6859

Subramanian, M., and Tabas, I. (2014). Dendritic cells in atherosclerosis. Semin. Immunopathol. 36, 93-102. doi: 10.1007/s00281-013-0400-x

Takeda, M., Yamashita, T., Sasaki, N., and Hirata, K. I. (2012). Dendritic cells in atherogenesis: possible novel targets for prevention of Atherosclerosis. J. Atheroscler. Thromb. 19, 953-961. doi: 10.5551/jat. 14134

Tuttolomondo, A., Di Raimondo, D., Pecoraro, R., Arnao, V., Pinto, A., and Licata, G. (2012). Atherosclerosis as an inflammatory disease. Curr. Pharm. Des. 18, 4266-4288. doi: 10.2174/138161212802481237

Van Brussel, I., Lee, W. P., Rombouts, M., Nuyts, A. H., Heylen, M., De Winter, B. Y., et al. (2014). Tolerogenic dendritic cell vaccines to treat autoimmune diseases: can the unattainable dream turn into reality? Autoimmun. Rev. 13, 138-150. doi: 10.1016/j.autrev.2013.09.008

Van Brussel, I., Schrijvers, D. M., Van Vré, E. A., and Bult, H. (2013). Potential use of dendritic cells for anti-atherosclerotic therapy. Curr. Pharm. Des. 19, 5873-5882. doi: 10.2174/1381612811319330006

VanderLaan, P. A., Reardon, C. A., Sagiv, Y., Blachowicz, L., Lukens, J., Nissenbaum, M., et al. (2007). Characterization of the natural killer T-cell response in an adoptive transfer model of atherosclerosis. Am. J. Pathol. 170, 1100-1107. doi: 10.2353/ajpath.2007.060188

van Es, T., van Puijvelde, G. H., Foks, A. C., Habets, K. L., Bot, I., Gilboa, E., et al. (2010). Vaccination against Foxp3 $(+)$ regulatory $\mathrm{T}$ cells aggravates atherosclerosis. Atherosclerosis 209, 74-80. doi: 10.1016/j.atherosclerosis.2009. 08.041

van Leeuwen, M., Damoiseaux, J., Duijvestijn, A., and Tervaert, J. W. (2009). The therapeutic potential of targeting B cells and anti-oxLDL antibodies in atherosclerosis. Autoimmun. Rev. 9, 53-57. doi: 10.1016/j.autrev.2009. 03.001

van Puijvelde, G. H., Hauer, A. D., de Vos, P., van den Heuvel, R., van Herwijnen, M. J., van der Zee, R., et al. (2006). Induction of oral tolerance to oxidized lowdensity lipoprotein ameliorates atherosclerosis. Circulation 114, 1968-1976. doi: 10.1161/CIRCULATIONAHA.106.615609
Van Vré, E. A., Van Brussel, I., Bosmans, J. M., Vrints, C. J., and Bult, H. (2011). Dendritic cells in human atherosclerosis: from circulation to atherosclerotic plaques. Mediators Inflamm. 2011, 941396. doi: 10.1155/2011/941396

Villadangos, J. A., and Young, L. (2008). Antigen-presentation properties of plasmacytoid dendritic cells. Immunity 29, 352-361. doi: 10.1016/j.immuni.2008.09.002

Weber, C., Meiler, S., Döring, Y., Koch, M., Drechsler, M., Megens, R. T., et al.(2011). CCL17-expressing dendritic cells drive atherosclerosis by restraining regulatory $\mathrm{T}$ cell homeostasis in mice. J. Clin. Invest. 121, 2898-2910. doi: 10.1172/JCI44925

Yamanaka, R., and Kajiwara, K. (2012). Dendritic cell vaccines. Adv. Exp. Med. Biol. 746, 187-200. doi: 10.1007/978-1-4614-3146-6_15

Yilmaz, A., Lochno, M., Traeg, F., Cicha, I., Reiss, C., Stumpf, C., et al. (2004). Emergence of dendritic cells in rupture-prone regions of vulnerable carotid plaques. Atherosclerosis 176, 101-110. doi: 10.1016/j.atherosclerosis.2004.04.027

Yilmaz, A., Weber, J., Cicha, I., Stumpf, C., Klein, M., Raithel, D., et al. (2006). Decrease in circulating myeloid dendritic cell precursors in coronary artery disease. J. Am. Coll. Cardiol. 48, 70-80. doi: 10.1016/j.jacc.2006.01.078

Zhou, X., Robertson, A. K., Hjerpe, C., and Hansson, G. K. (2006). Adoptive transfer of $\mathrm{CD} 4+\mathrm{T}$ cells reactive to modified low-density lipoprotein aggravates atherosclerosis. Arterioscler. Thromb. Vasc. Biol. 26, 864-870. doi: 10.1161/01.ATV.0000206122.61591.ff

Conflict of Interest Statement: The authors declare that the research was conducted in the absence of any commercial or financial relationships that could be construed as a potential conflict of interest.

Received: 12 February 2014; accepted: 09 May 2014; published online: 27 May 2014. Citation: Chistiakov DA, Sobenin IA, Orekhov AN and Bobryshev YV (2014) Dendritic cells in atherosclerotic inflammation: the complexity of functions and the peculiarities of pathophysiological effects. Front. Physiol. 5:196. doi: 10.3389/fphys. 2014.00196

This article was submitted to Vascular Physiology, a section of the journal Frontiers in Physiology.

Copyright (c) 2014 Chistiakov, Sobenin, Orekhov and Bobryshev. This is an openaccess article distributed under the terms of the Creative Commons Attribution License (CC BY). The use, distribution or reproduction in other forums is permitted, provided the original author(s) or licensor are credited and that the original publication in this journal is cited, in accordance with accepted academic practice. No use, distribution or reproduction is permitted which does not comply with these terms. 